\title{
Ocean circulation in a warming climate
}

\author{
J. R. Toggweiler \& Joellen Russell
}

\section{Climate models predict that the ocean's circulation will weaken in response to global warming, but the warming at the end of the last ice age suggests a different outcome.}

There is an old truism in climate circles that the cold climate at the Last Glacial Maximum (LGM), which occurred 21,000 years ago, had stronger winds. This idea fits with the common observation that it is windier in the winter than in the summer because there is greater thermal contrast within the atmosphere in the winter hemisphere. Temperature reconstructions from the LGM show that Equator-to-pole gradients in sea surface temperature were indeed larger - that is, the polar oceans were colder than the tropical ocean at the LGM in comparison with the temperature differences today.

It is now becoming clear that the winds in the atmosphere drive most of the circulation in the ocean. If the LGM climate really did have stronger winds, it would thus be expected that the circulation in the ocean was more vigorous. The oceans seem to tell a different story, however. The deep water in the ocean's interior is continuously being replaced ('overturned') by surface waters from the poles. This overturning circulation in the Atlantic Ocean seems to have been weaker at the $\mathrm{LGM}^{1}$. The water in the deep ocean was also very 'old' in relation to the atmosphere - in terms of having a low radiocarbon content - indicating that the ocean's interior was poorly mixed and poorly ventilated ${ }^{2}$. The overturning circulation then seems to have strengthened as Earth began to warm about 18,000 years ago. The increased overturning vented the radiocarbon-depleted carbon dioxide $\left(\mathrm{CO}_{2}\right)$ to the atmosphere, as seen in a pair of big dips in the radiocarbon activity of the atmosphere and upper ocean ${ }^{3}$. This addition of $\mathrm{CO}_{2}$ to the atmosphere helped to warm the climate and bring the last ice age to an end.

These findings present a conundrum. If the winds were stronger in the cold glacial state and became weaker going into the warm interglacial state, then why was the ocean's circulation weaker during the cold glacial period? And how did it increase in strength during the transition to the warm interglacial period, causing the ocean's interior to become better mixed and better ventilated? Are researchers missing something about the factors that affect ocean circulation, or is it the old truism about the strength of the winds during the cold glacial period that is flawed?

During the 1990s, the first generation of coupled climate models predicted that the ocean's overturning circulation would weaken markedly over the next 100-200 years in response to global warming ${ }^{4}$. The predicted weakening is a response to the warming itself and to a stronger hydrological cycle, both of which make the ocean surface waters in the models less dense and less able to sink in relation to the water below. Thus, the models suggested that circulation would be less vigorous in a warming climate, somewhat like the weakening expected from diminished winds in a warmer climate outlined above. But again, the real ocean became better mixed and better ventilated when Earth began to warm about 18,000 years ago. So what will happen to the ocean's circulation in a warming climate? Are the models getting it wrong?

\section{Winds and the ocean's overturning circulation}

Until recently, the circulation of the ocean was thought to comprise two fairly independent parts. The wind-driven circulation drove the surface currents in the ocean gyres, whereas the overturning circulation ventilated the interior with cold and relatively saline water from the poles. The latter was called the 'thermohaline' circulation to emphasize that it was driven by buoyancy forces - warming, cooling, freshening and salinification - rather than the stress on the surface coming from the winds.

The inconsistencies mentioned earlier could be overlooked if this dichotomy holds, because the winds and the wind-driven circulation in the upper ocean could still have been stronger during the LGM while the thermohaline circulation was less vigorous. However, the dichotomy and the use of the term 'thermohaline' have almost disappeared from the oceanographic literature, because the circulation in the interior is now increasingly seen as being driven by turbulent mixing from the winds and tides ${ }^{5,6}$ and directly by the winds themselves ${ }^{7}$.

The westerly winds over the Southern Ocean seem to be crucial in this regard $^{7}$. The Antarctic Circumpolar Current (ACC) is a wind-driven current that goes around Antarctica through an east-west channel between South America, Australia and Antarctica that is not blocked by land. Because the winds over the channel and the flow of the ACC are aligned for the length of the channel, the ACC is easily the world's strongest current (by volume of water transported). According to Carl Wunsch ${ }^{8}$, about $70 \%$ of the wind energy going into ocean currents globally goes directly into the ACC.

The same dense water found in the interior north of the ACC is also found just below the surface around Antarctica, and the westerly winds driving the ACC draw this dense water directly up to the surface (Fig. 1). In this way, the winds driving the ACC continually remove dense water from the interior. Dense water must sink elsewhere to replace the water drawn up by the winds around Antarctica.

The ACC is constrained to flow south of the tip of South America at $56^{\circ} \mathrm{S}$ as it passes from the Pacific Ocean to the Atlantic Ocean. Its mean position therefore lies between $50^{\circ} \mathrm{S}$ and $55^{\circ} \mathrm{S}$. The strongest westerly winds tend to be found between $45^{\circ} \mathrm{S}$ and $50^{\circ} \mathrm{S}$. This means that the strongest westerly winds are not actually aligned with the ACC. It is noteworthy in this regard that the westerly winds in both hemispheres have been shifting polewards and getting stronger over the past 40 years ${ }^{9,10}$, partly in response to the warming from higher atmospheric $\mathrm{CO}_{2}$ concentrations $^{11,12}$. Thus, the strongest westerlies are now more squarely over the ACC, and - as expected - they seem to be doing more work to drive the ACC and more work to draw deep water up to the surface than they were 40 years ago ${ }^{13,14}$.

Measurements south of Australia indicate that the ACC has strengthened since the 1960s and 1970s (ref. 15). The ocean's surface stands higher north of the ACC and lower south of the ACC than it did in the 1960 s and 1970s, and changes in subsurface water properties show the pattern expected from a stronger wind effect (Fig. 1).

The first generation of climate models suggested that warmer ocean temperatures and the freshening of the polar oceans are the primary influences on the ocean's overturning circulation in a warming climate. Warmer ocean temperatures lead to more evaporation from the tropical ocean and more freshwater input to the polar oceans through precipitation and runoff from the land; that is, a stronger hydrological cycle. According to these models, polar freshening should have already led to 


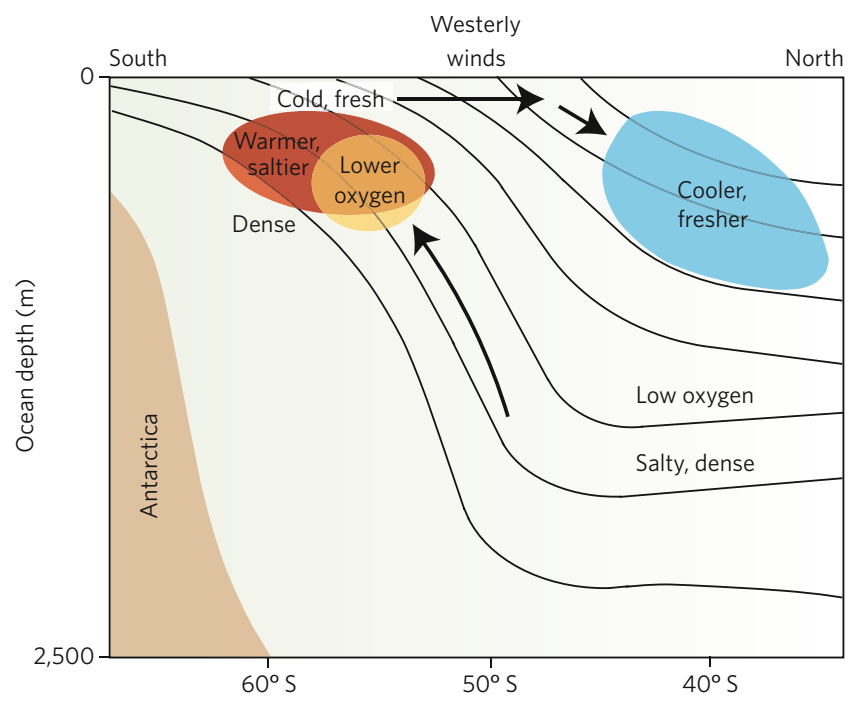

Figure 1 Cross-section of the ACC, illustrating how stronger winds over the ACC lead to a stronger overturning circulation. The curved lines are isolines of constant density. These lines plunge downwards and to the north, reflecting the flow of the current (out of the page in the centre of the figure). Westerly winds above the ACC (also blowing out of the page) push cold, fresh surface waters away from Antarctica across the ACC (towards the blue area) and draw slightly warmer and salty water that is low in oxygen up from the interior to the surface (towards the red and yellow areas). Stronger winds in the past 40 years have resulted in more surface water being pushed northwards and have drawn more deep water up to the surface. As a result, the water just below the surface around Antarctica is now warmer, saltier and lower in oxygen, despite an overall freshening of the ocean around Antarctica. The water in the blue area to the north has become cooler and fresher. (Figure adapted from ref. 15.)

some weakening of the overturning and more stratification of the polar oceans in both hemispheres ${ }^{16}$. There is no firm evidence yet that this has happened ${ }^{17}$, possibly because stronger winds have maintained the circulation of salty water into the regions where sinking occurs. The first generation of climate models had weak winds and sluggish wind-driven circulations, and the winds in these models did not change with higher atmospheric $\mathrm{CO}_{2}$. Thus, the hydrological cycle in the early models had a free rein to slow the overturning as the climate warmed.

The climate models in the latest round of assessments by the Intergovernmental Panel on Climate Change predict that the westerlies will shift polewards and become stronger in the twenty-first century ${ }^{18}$. However, the models still suggest that the overturning of the Atlantic Ocean will weaken, although not nearly as much as in the first generation of climate models ${ }^{19}$.

\section{Role of temperature gradients}

The poleward shift and the intensification of the westerlies over the past 40 years caught geoscientists by surprise. Because a higher atmospheric $\mathrm{CO}_{2}$ concentration is supposed to warm the poles more than the tropics, the intensification, in particular, was not predicted. An important consideration in this regard is that the westerlies respond mainly to changes in the thermal contrast in the middle of the atmosphere rather than to changes at the surface, and the thermal contrast in the middle of the atmosphere has increased in response to higher $\mathrm{CO}_{2}$ levels ${ }^{12}$.

A schematic illustration of the structure of the atmosphere is shown in Fig. 2, indicating how the atmosphere varies in response to higher $\mathrm{CO}_{2}$ concentrations. $\mathrm{CO}_{2}$ makes the atmosphere more opaque to outgoing long-wave radiation. More $\mathrm{CO}_{2}$ warms the pocket of warm air near the surface in the tropics and subtropics, and cools the envelope of cold air above the tropics and subtropics and over the poles ${ }^{12}$. The position and strength of the westerlies reflect the thermal contrast between the pocket of warm air and the envelope of cold air.

At the LGM, a time of low atmospheric $\mathrm{CO}_{2}$ concentrations, the pocket of warm air was cooler and probably did not extend as far above the surface at low latitudes (Fig. 2b). This is consistent with the depression of the snowline seen on tropical mountains ${ }^{20}$. At the same time, the envelope of cold air should have been relatively warm. Thus, the thermal contrast in the middle of the atmosphere would have been relatively weak. From this perspective, weaker, not stronger, westerlies would be expected at the LGM.

The amount of $\mathrm{CO}_{2}$ in the atmosphere increased at the end of the last ice age and is increasing again today. This increase seems to have warmed the pocket of warm air and caused it to expand upwards (Fig. 2a), whereas the envelope of cold air has cooled ${ }^{12}$. It is thought that the upward expansion and the cooling aloft have led to greater thermal contrast in the middle of the atmosphere, which has increased the strength of the mid-latitude westerlies and caused them to shift towards the poles. The wind stress on the ocean has become stronger and the position of maximum stress has shifted polewards in response to these changes in the westerly flow aloft.

At the LGM, by contrast, the strongest westerlies in the Southern Hemisphere seem to have been about $7-10^{\circ}$ north of their modern position $^{21}$. Because the ACC cannot change its position, a shift of this magnitude towards the Equator would have put the westerlies well to the north of the ACC, in a position where they could not put much energy into the ACC or the overturning circulation. A poleward shift and an intensification of the westerlies during the warming at the end of the last ice age would have put stronger westerlies closer to the ACC and might thus have enhanced the ocean's circulation, as postulated earlier.

\section{Ocean temperatures and the ozone hole}

Two factors make the warming at the end of the last ice age and the warming today rather different. One is the rate of warming. The other factor is the ozone hole over Antarctica.

The temperature of the ocean is a crucial factor for the overturning, because the density of sea water responds more strongly to temperature when the ocean is warm and responds more strongly to salinity when the ocean is cold. The polar oceans were very cold at the peak of the last ice age. At these low temperatures, the overturning would have been very sensitive to inputs of fresh water near the poles ${ }^{22,23}$. Indeed, a cap of cold, fresh polar surface waters and extensive sea ice seems to have blocked the overturning around Antarctica and trapped a large quantity of radiocarbon-depleted $\mathrm{CO}_{2}$ in the deep ocean ${ }^{24}$. As the ocean warmed and the westerlies shifted polewards, the cap seems to have broken down and released this $\mathrm{CO}_{2}$ to the atmosphere ${ }^{21}$.

The warming and the release of $\mathrm{CO}_{2}$ at the end of the last ice age were spread over several thousand years. At this pace, all the different parts of the ocean would presumably have warmed together. Most of the warming in the future, however, is expected to happen in the next 200 years. Thus, much of the future warming in the ocean could be confined to the ocean's surface layers. A surface-confined warming would work together with the hydrological cycle to weaken the overturning. However, if stronger winds can maintain the overturning, the warming in the future will be more evenly distributed through the ocean and not be as much of a factor.

The shift in the westerlies over the past 40 years has been asymmetrical, with a much larger shift in the south than in the north. The asymmetry is due at least partly to the depletion of stratospheric ozone over Antarctica, which was caused by the emission of long-lived chlorofluorocarbons during the twentieth century. Removing the ozone from the lower stratosphere is an effective way to cool the envelope of cold air over Antarctica (Fig. 2). Thus, the depletion of ozone, like the increase in $\mathrm{CO}_{2}$ concentration, has increased the thermal contrast in the south and helped to make the southern westerlies stronger ${ }^{25}$.

The amount of ozone should be returning to previous levels over the next 40 years. This means that the wind effect on the ocean's overturning due to ozone depletion should be tailing off as the wind effect due to $\mathrm{CO}_{2}$ continues to increase. Thus, the wind effect on the overturning might not be increasing as much over the next 40 years as it did over the past 40 years. 


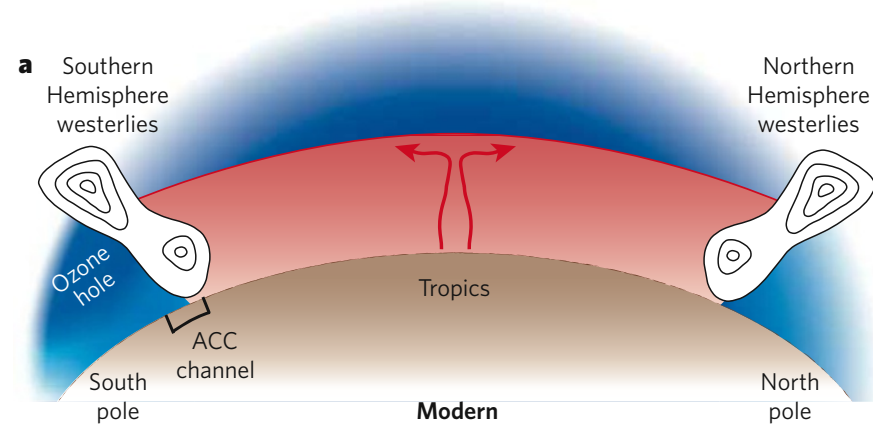

b

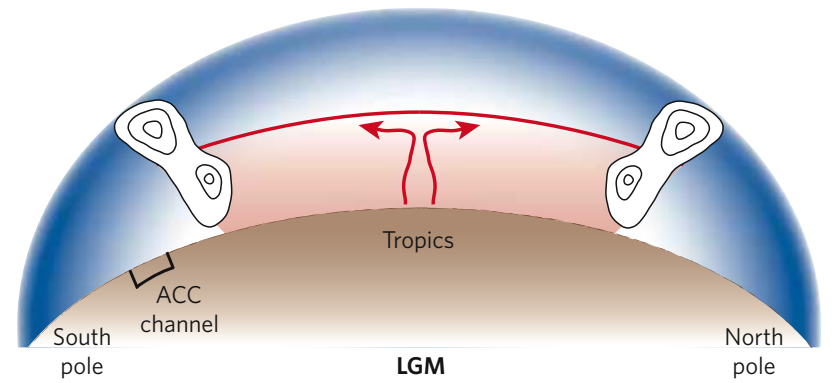

Figure 2 | Changes in the westerlies and atmospheric structure in response to different $\mathrm{CO}_{2}$ concentrations. Bands of westerly winds in the Northern Hemisphere and Southern Hemisphere (shown schematically by the isotachs) separate the warm air (red shades) in the tropics from the cold air (blue shades) over the poles. a, Atmospheric structure today. Over recent decades, higher $\mathrm{CO}_{2}$ concentrations have made the warm air warmer and the surrounding envelope of cold air cooler, especially near the top of the troposphere (curved red line). The thermal contrast across the zones of strong westerlies in the Northern and Southern Hemispheres is therefore greater, and the westerlies have become stronger and have shifted polewards in response. b, Proposed atmospheric structure at the LGM. With less $\mathrm{CO}_{2}$ in the atmosphere, the thermal contrast in the middle of the atmosphere was probably decreased (indicated by paler shades), and the westerlies aloft should therefore have been relatively weak. The strongest westerlies were also significantly north of the ACC, where they would have had much less impact on the ocean.

\section{Lessons from the past}

Anthropogenic additions of $\mathrm{CO}_{2}$ to the atmosphere have resulted in a stronger hydrological cycle and a warming of the upper ocean that are currently threatening to weaken the ocean's overturning circulation. However, larger differences in temperature in the middle of the atmosphere have given rise to stronger winds that are acting to strengthen the circulation, as we argue they did at the end of the last ice age. What is uncertain is whether stronger winds and a stronger circulation will counter the freshening and distribute the extra heat through the interior over the next 200 years.

Current climate-system models say that the ocean's overturning circulation will weaken over the next century ${ }^{19}$, but these predictions might not rest on a solid foundation. The early climate models were deficient because they understated the effects of the winds in general and failed to anticipate the poleward shift and the intensification of the westerlies over the past 40 years. The latest models are much improved but might still not fully represent the wind effect.

A key test for the models is to reproduce the changes that took place at the end of the last ice age. Does the oceanic circulation in the models get weak enough in a cold LGM-like state to bottle up so much $\mathrm{CO}_{2}$ ? More importantly, can the weaker circulation make the $\mathrm{CO}_{2}$ in the deep ocean very old with respect to the radiocarbon activity in the atmosphere ${ }^{2}$ ? Can the circulation then get strong enough to let all the radiocarbon-depleted $\mathrm{CO}_{2}$ back out? From the observations, it is clear that large circulation changes took place, and it seems unlikely that circulation changes of this magnitude could have happened without substantial changes in the wind forcing. It seems that the information from the past is telling us to expect a stronger oceanic circulation in the warmer climate to come.

J. R. Toggweiler is at the Geophysical Fluid Dynamics Laboratory, National Oceanic and Atmospheric Administration, Princeton, New Jersey 08542, USA. Joellen Russell is in the Department of Geosciences, University of Arizona, Tucson, Arizona 85721, USA.

1. Lynch-Stieglitz, J. et al. Atlantic meridional overturning during the Last Glacial Maximum. Science 316, 66-69 (2007)

2. Sikes, E. L., Samson, C. R., Guilderson, T. P. \& Howard, W. R. Old radiocarbon ages in the Southwest Pacific at 11,900 years ago and the last glaciations. Nature $405,555-559$ (2000).

3. Marchitto, T. M., Lehman, S. J., Ortiz, J. D., Fluckiger, J. \& van Geen, A. Marine radiocarbon evidence for the mechanism of deglacial atmospheric $\mathrm{CO}_{2}$ rise. Science 316, 1456-1459 (2007).

4. Manabe, S. \& Stouffer, R. J. Century-scale effects of increased atmospheric $\mathrm{CO}_{2}$ on the ocean-atmosphere system. Nature 364, 215-218 (1993).

5. Munk, W. \& Wunsch, C. Abyssal recipes II: energetics of tidal and wind mixing. Deep-Sea Res. / 45, 1977-2010 (1998).

6. Kuhlbrodt, T. et al. On the driving processes of the Atlantic meridional overturning circulation. Rev. Geophys. 45, RG2001, doi:10.1029/2004RG000166 (2007).

7. Toggweiler, J. R. \& Samuels, B. Effect of Drake Passage on the global thermohaline circulation. Deep-Sea Res. / 42, 477-500 (1995).

8. Wunsch, C. Work done by the wind on the oceanic general circulation. J. Phys. Oceanogr. 28, 2332-2340 (1998)

9. Hurrell, J. W. \& van Loon, H. A modulation of the atmospheric annual cycle in the Southern Hemisphere. Tellus A 46, 325-338 (1994).

10. McGabe, G. J., Clark, M. P. \& Serreze, J. C. Trends in Northern Hemisphere surface cyclone frequency and intensity. J. Clim. 14, 2763-2768 (2001).

11. Gillett, N. P., Zwiers, F. W., Weaver, A. J. \& Stott, P. A. Detection of human influence on sea level pressure. Nature 422, 292-294 (2003).

12. Shindell, D. T. \& Schmidt, G. A. Southern Hemisphere climate response to ozone changes and greenhouse gas increases. Geophys. Res. Lett. 31, L18209, doi:10.1029/2004GL020724 (2004).

13. Saenko, O. A., Fyfe, J. C. \& England, M. H. On the response of the ocean wind-driven circulation to atmospheric $\mathrm{CO}_{2}$ increase. Clim. Dyn. 25, 415-426 (2005).

14. Russell, J. L., Dixon, K. W., Gnanadesikan, A., Stouffer, R. J. \& Toggweiler, J. R. The Southern Hemisphere westerlies in a warming world: Propping open the door to the deep ocean. J. Clim. 19, 6382-6390 (2006).

15. Aoki, S., Bindoff, N. L. \& Church, J. A. Interdecadal water mass changes in the Southern Ocean between $30^{\circ}$ E and $160^{\circ} \mathrm{E}$. Geophys. Res. Lett. 32, L07607, doi:10.1029/2004GL022220 (2005).

16. Sarmiento, J. L., Hughes, T. M. C., Stouffer, R. J. \& Manabe, S. Simulated response of the ocean carbon cycle to anthropogenic climate warming. Nature 393, 245-249 (1998).

17. Bindoff, N. L. et al. in Climate Change 2007: The Physical Science Basis. Contribution of Working Group I to the Fourth Assessment Report of the Intergovernmental Panel on Climate Change (eds Solomon, S. et al.) 385-432 (Cambridge Univ. Press, Cambridge, UK, 2007)

18. Yin, J. H. A consistent poleward shift of the storm tracks in simulations of 21st century climate. Geophys. Res. Lett. 32, L18701, doi:10.1029/2005GL023684 (2005).

19. Gregory, J. M. et al. A model intercomparison of changes in the Atlantic thermo-haline circulation in response to increasing atmospheric $\mathrm{CO}_{2}$ concentration. Geophys. Res. Lett. 32 L12703, doi:10.1029/2005GL023209 (2005).

20. Broecker, W. S. \& Denton, G. H. The role of ocean-atmosphere reorganizations in glacial cycles. Geochim. Cosmochim. Acta 53, 2465-2501 (1989).

21. Toggweiler, J. R., Russell, J. L. \& Carson, S. R. Midlatitude westerlies, atmospheric $\mathrm{CO}_{2}$ and climate change during the ice ages. Paleoceanography 21, PA2005, doi:10.1029/ 2005PA001154 (2006)

22. Sigman, D. M., Jaccard, S. L. \& Haug, G. H. Polar ocean stratification in a cold climate. Nature 428, 59-63 (2004)

23. De Boer, A. M., Sigman, D. M., Toggweiler, J. R. \& Russell, J. L. Effect of global ocean temperature changed on deep ocean ventilation. Paleoceanography 22, PA2210, doi:10.1029/2005PA001242 (2007).

24. Francois, R. F. et al. Water column stratification in the Southern Ocean contributed to the lowering of glacial atmospheric $\mathrm{CO}_{2}$. Nature 389, 929-935 (1997).

25. Thompson, D. W. J. \& Solomon, S. Interpretation of recent Southern Hemisphere climate change. Science 296, 895-899 (2002)

Acknowledgements We thank I. Held and M. Wallace for critical insights, A. Gnanadesikan for comments on the manuscript, and C. Raphael and J. Varanyak for help with the figures. J.R.'s work was supported by a grant from the National Oceanic and Atmospheric Administration.

Author Information Reprints and permissions information is available at npg.nature.com/reprints. Correspondence should be addressed to J.R.T. (robbie.toggweiler@noaa.gov). 